\title{
COMPARATIVE STUDY OF POST-DURAL PUNCTURE HEADACHE USING TWO TYPES OF NEEDLES QUINCKE'S AND WHITACRE
}

\author{
Sumitra Kanojiya1, Vibha Mehta², V. P. Jadhav³
}

${ }^{1}$ Associate Professor, Department of Anaesthesia, MAMC, Agroha, Hisar.

${ }^{2}$ Associate Professor, Department of Anaesthesia, MAMC, Agroha, Hisar.

${ }^{3}$ Professor and HOD, Department of Anaesthesia, KIMS, Karad, Maharashtra.

\section{ABSTRACT}

\section{BACKGROUND}

Post-dural puncture headache has been a problem following dural puncture since August Bier reported the first case in 1898. Occurrence of PDPH is influenced by age, sex, needle size, needle tip design and number of dural puncture.

\section{MATERIAL AND METHODS}

A total of 200 patients were studied and divided into two groups. Group " $Q$ " (n=100) where dural puncture was carried by using Quincke's needle (25 G) and group "W" ( $n=100)$ where dural puncture was carried by using Whitacre needle (25 G). We obtained the approval of ethical committee.

\section{OBSERVATIONS AND RESULTS}

The rates of PDPH were statistically different between both the groups; 7\% patients developed PDPH in group "Q" and 0\% in group "W." The intensity was mild in $1 \%$ of patients, moderate in $4 \%$ of patients and severe in $2 \%$ of patients in group "Q."

\section{DISCUSSION}

In spite of using small bore needle (26 G), PDPH still occurs. So present study compares the incidence of PDPH by using Quincke's and Whitacre needle, keeping the needle size same.

\section{KEYWORDS}

PDPH, Quincke's Needle, Whitacre Needle, Post-Dural Puncture Backache (PDPB).

HOW TO CITE THIS ARTICLE: Kanojiya S, Mehta V, Jadhav VP. Comparative study of post-dural puncture headache using two types of needles Quincke's and Whitacre. J. Evolution Med. Dent. Sci. 2016;5(32):1707-1709, DOI: 10.14260/jemds/2016/402

\section{INTRODUCTION}

Post-Dural Puncture Headache (PDPH) a well-known complication of spinal anaesthesia. The incidence of PDPH depends on many factors such as age, sex, pregnancy, previous history of PDPH, needle size, shape and needle bevel orientation to the dural fibers, number of dural puncture attempts and clinical experience of anaesthetist.1,2,3,4,5,6,7

Quincke's needle is the standard spinal anaesthetic needle with a cutting tip. The bevel shape facilitates its progression through the skin, subcutaneous tissue and ligaments. However, the cutting tip may result in a great dural matter damage and eventual PDPH. PDPH occurs more frequently in cutting than in pencil point needle even when smaller bore cutting needle is used as compared to large bore pencil point needle. ${ }^{8}$

In this study, we try to determine whether the needle tip design is effective in reducing PDPH by comparing incidence of PDPH using Quincke's needle and Whitacre needle, keeping the size of the needle same, i.e. 25G.

\section{AIMS AND OBJECTIVES}

Our aim is to study incidence of PDPH using two types of spinal needles, i.e. Quincke's and Whitacre needle.

Financial or Other, Competing Interest: None.

Submission 04-03-2016, Peer Review 30-03-2016,

Acceptance 05-04-2016, Published 20-04-2016.

Corresponding Author:

Dr. Sumitra Kanojiya,

House No. 61, Chanderlane Colony,

Kaimri Road, Hisar

Haryana.

E-mail: drsumitrakanojiya@gmail.com

DOI: 10.14260/jemds/2016/402
We also compared the incidence of other complications like Post-Dural Puncture Backache (PDPB).

\section{MATERIALS AND METHODS}

After the local institutional board approval and clinical trials, a total of 200 patients were studied and randomly divided into two groups. Group Q- where dural puncture was carried by Quincke's needle (25 G) and group W- where dural puncture was carried by Whitacre needle $25 \mathrm{G}$. The patients between age groups of 20-60 years of ASA-I and ASA-II physical status of either sex who were posted for lower abdominal surgery, perineal and lower limb surgeries elective as well as emergency were included in the study. Exclusion criteria were denial of the patient for spinal anaesthesia, primary headache disorders (e.g. migraine), haemostatic disorders, infection at the site of puncture, pre-existing neurological deficit of lower limb and those receiving anticoagulants. Obstetric patients and patients, which required multiple attempts for spinal anaesthesia were also excluded from the study.

A written informed consent of the patient was taken They were explained about the procedure and technique for spinal anaesthesia. All the patients were preloaded with 15-20 $\mathrm{mL} / \mathrm{kg}$ of physiological saline solution prior to the procedure. Routine intraoperative monitors included continuous ECG, pulse oximetry, NIBP monitoring. Lumbar puncture was performed at L3-4 intervertebral space in right or left lateral position under all aseptic precautions. All the patients were given spinal anaesthesia by median approach using hyperbaric $0.5 \%$ Sensorcaine. The level was maintained at T6 level in all the patients. Intraoperatively pulse rate, blood pressure, respiratory rate, ECG monitoring was done. Patients were also inquired about any headache half hourly intraoperatively as 
well as postoperatively till they shifted to ward.

After the surgery, the patients were shifted to postoperative recovery room on a head low trolley. They were kept in a recovery room for a minimum duration of 2 hours. Only when they were able to move their lower limbs, they were shifted to the wards. All the patients were kept in head low position. In the wards, they were followed for 5 days. First visit was made in the evening 6-8 hours after surgery. All the patients were questioned about any subjective symptoms of headache, nausea, vomiting and backache.

Those complaining of headache were asked about location, nature and severity of headache, whether worsened by sitting, coughing and relieved by lying down. They were asked to mark on visual analogue scale, the intensity and severity of headache. The degree of pain was assessed with the help of Visual Analogue Scale (VAS).

\begin{tabular}{|c|c|}
\hline $\begin{array}{c}\text { Marking of Visual } \\
\text { Analogue Scale } \mathbf{C m} \text { Cm }\end{array}$ & $\begin{array}{c}\text { Degree } \\
\text { of Pain }\end{array}$ \\
\hline $0-3$ & Mild \\
\hline $4-7$ & Moderate \\
\hline$>7$ & Severe \\
\hline
\end{tabular}

Following methods of treatment were instituted to the patients according to the severity of the headache. Initially head low position, strict bed rest and adequate hydration were advised. Patients taking oral intake were encouraged to drink plenty of oral fluids. If no relief, IV fluids were given in addition to oral intake. If these measures also failed, analgesics like Tab. Diclofenac sodium + paracetamol (50 mg+ $500 \mathrm{mg} \mathrm{BD}$ ) or Tab. Nimesulide (100 mg BD) along with other measures were given. All the patients had reduction in the severity to tolerable levels with this line of treatment.

\section{OBSERVATION AND RESULTS}

A total of 200 patients were studied, hundred patients in each group assigned randomly to receive spinal anaesthesia either by using Quincke's needle (100 patients, group ' $Q$ ') or Whitacre needle (100 patients, 'W' group) for performing lumbar puncture. The demographic data of the patients are shown in Table 1. No difference was found with regard to age, sex, weight of the patients between the two groups.

\begin{tabular}{|c|c|c|}
\hline Groups & $\begin{array}{c}\text { Group } \\
\mathbf{Q}\end{array}$ & $\begin{array}{c}\text { Group } \\
\text { W }\end{array}$ \\
\hline Age Males & $33.42 \pm 3.83$ & $37.40 \pm 3.86$ \\
\hline Females & $32.89 \pm 3.70$ & $38.10 \pm 3.81$ \\
\hline Weight & $50.12 \pm 5.07$ & $51.97 \pm 5.13$ \\
\hline \multicolumn{2}{|c|}{ Table 1: Demographic Data of the Patients } \\
\hline
\end{tabular}

Table 2 shows the incidence of PDPH in two groups.7\% (Seven) patients had PDPH in group ' $Q$ ' as compared to no patient in group ' $W$ ' (o patient), i.e. all the patients in whom PDPH occurred belonged to ' $Q$ ' group. Maximum incidence was observed in 20-30 years of age group. In group $Q$ only one patient had onset of PDPH within 24 hours, while 6 patients had PDPH within 25-48 hours postoperatively.

\begin{tabular}{|c|c|c|c|c|}
\hline $\begin{array}{c}\text { Age } \\
\text { in Years }\end{array}$ & \multicolumn{2}{|c|}{ Group Q } & \multicolumn{2}{c|}{ Group W } \\
\hline & M & F & M & F \\
\hline $20-30$ & 3 & 3 & 0 & 0 \\
\hline $31-40$ & - & - & 0 & 0 \\
\hline $41-50$ & - & - & 0 & 0 \\
\hline $51-60$ & 0 & 1 & 0 & 0 \\
\hline \multicolumn{2}{|c|}{ Table 2: Incidence of PDPH in Two Groups } \\
\hline
\end{tabular}

The intensity of PDPH was mild in $1 \%$ of patients, moderate in $4 \%$ of patients and severe in $2 \%$ of patients in group 'Q.' None of the patient had PDPH in group 'W.'

\begin{tabular}{|c|c|c|}
\hline PDPH & Group Q & Group W \\
\hline None & 93 & 100 \\
\hline Mild & $1(1 \%)$ & - \\
\hline Moderate & $4(4 \%)$ & - \\
\hline Severe & $2(2 \%)$ & - \\
\hline \multicolumn{2}{|c|}{ Table 3: Incidence and Severity of } \\
PDPH in the Two Groups \\
\hline
\end{tabular}

15 patients had post-dural puncture backache in both the groups. In group ' $Q$ ', 10 patients had nausea, 8 had vomiting and 10 had shivering. In group ' $W$,' 12 had nausea, 10 had vomiting and 12 had shivering since the $P$ value in $>0.05$. The difference is statistically not significant.

\begin{tabular}{|c|c|c|c|c|}
\hline $\begin{array}{c}\text { Immediate } \\
\text { Postop } \\
\text { Complications }\end{array}$ & $\begin{array}{c}\text { Group } \\
\text { 'Q' }\end{array}$ & $\begin{array}{c}\text { Group } \\
\text { 'W' }\end{array}$ & $\begin{array}{c}\text { Chi } \\
\text { Square } \\
\text { Test }\end{array}$ & $\begin{array}{c}\text { P } \\
\text { value }\end{array}$ \\
\hline PDPB & 15 & 15 & 0 & 1 \\
\hline Nausea & 10 & 12 & 0.204 & 0.651 \\
\hline Vomiting & 8 & 10 & 0.244 & 0.621 \\
\hline Shivering & 10 & 12 & 0.204 & 0.651 \\
\hline Table 4: Other Complications with Spinal Anaesthesia \\
\hline
\end{tabular}

\section{DISCUSSION}

Spinal anaesthesia is one of the most commonly used anaesthesia for lower abdominal, perineal and lower limb surgeries. However, one of the drawbacks of spinal anaesthesia is occurrence of post-dural puncture headache. Since the time, it has been realized that aetiology of PDPH could be leakage of CSF through the dural hole into the epidural space; insistence was put on using small bore needle and restricting the number of punctures to single one. In spite of using small bore needle (26 G), PDPH still occurs. So the recent interest has been on the needle tip design, which determines the type of hole, i.e. the cutting of dural fibers or separation of fibers without cutting them. PDPH occurs more frequently in cutting than in pencil point needle even when small bore cutting needle is used. ${ }^{8}$ compared to large bore pencil point needle. In this study, we have tried to determine whether the needle tip design is effective in reducing PDPH by comparing incidence of PDPH using two types of needles keeping size of needle same. We also compared the incidence of back pain and other symptoms after spinal anaesthesia.

The incidence of PDPH is greatest in age group 20-40 years and is less in old age. We have selected patients in age group 20-60 years. In our study, PDPH is most frequent in 2030 years of age group. Only one patient in 51-60 years of age 
had typical PDPH. Vandam and drips. ${ }^{9}$ reported maximum incidence of headache in 20-40 years of age group. Paramedian approach is more frequently associated with PDPH than median approach. ${ }^{10}$ for the same reason, all the patients under study received spinal anaesthesia through median approach.

Typical PDPH was observed in postoperative period in 7 patients in group ' $Q$,' whereas none of the patients in group ' $W$ ' had PDPH; 4 patients in PDPH patients were females and 3 were males. Corbey MP and et al. ${ }^{11}$ has shown similar results to our study. Other studies by Santanen U, Aautoma P, et al.12 Flatten $\mathrm{H}$ et al. ${ }^{13}$ have shown that the use of pencil point shaped needles significantly reduces the risk of PDPH as compared to Quincke's needle.

Typical PDPH occurs within an hour or two of anaesthesia, but onset may be delayed for some days and may last for weeks or even months. In our study, one patient had onset of PDPH within 24 hours and six patients had within 2448 hours in group 'Q.' Kumar CM and Dennison B.14 in 1986 noted PDPH within 3 days. In our study the duration of headache was between 48-72 hours in 2 patients, $72-96$ hours in 1 patient and $96-120$ hours in 4 patients. The intensity of headache can be related to the patient's pain threshold and psychology. ${ }^{15}$ In our study $1 \%$ patients had mild, 4\% patients had moderate and $2 \%$ patients had severe headache, all belonging to ' $Q$ ' group.

$72 \%$ of headache usually resolve within 7 days and $87 \%$ resolve in 6 months without any treatment. Prophylactic measures include proper selection of patient use of fine gauge needle, pencil point needle, preloading, bed rest for at least 24 hours, high abdominal binders to elevate intra-abdominal pressure which is transmitted to the epidural space. Supportive therapy by plenty of fluids (Oral, IV), analgesics like acetaminophen, NSAID, antiemetics, caffeine (IV/oral) can relieve headache. If not treated with supportive therapy, invasive procedures like epidural saline infusion, epidural blood patch can be used to raise the epidural pressure and treat PDPH. A danger of introducing infection also remains with such therapies. In our study, all the patients responded well to the supportive line of treatment. Severity of headache was reduced within 48-72 hours and all the patients were relieved of headache in five days.

Clinical evidence suggests that the pencil tip needle causes less dural damage than the beveled needle. Maximum extent of the dural lesion depends on the external diameter of the needle, dural healing mechanism, needle tip design and quality of needle polishing. The possible explanation for fewer incidences of PDPH with Whitacre may be given as the lesion produced in the arachnoid is such that it limits that leakage of CSF into the epidural space. Spinal needle designs continue to be studied and modified to reduce the incidence of PDPH in identified high risk groups.

\section{CONCLUSION}

Use of Whitacre needle for performing lumbar puncture is effective in preventing PDPH and should be used in preference to Quincke's needle. Other complications like PDPB, hypotension and shivering were similar in two groups and not significant. However, more study in larger patient groups are required to confirm result of this study.

\section{REFERENCES}

1. Lybecker H, Moller JT, Mayo, et al. Incidence and prediction of post dural puncture headache, a prospective study of 1021 spinal anaesthesia. Anaesthesia analgesia 1990;70(4):389-94.

2. Halpern S, Preston R. Post dural puncture headache and spinal needle design. Metanalysis Anaesthesiology 1994;81(6):1376-83.

3. Ross BK, Chadwick HS, Mancuso JJ, et al. Sprolte needle for obstetric anaesthesia decreased incidence of post dural puncture headache. Reg anaesthesia 1992;17(1):29-33.

4. Tarkkila PJ, Heine H, Tervo RR. Comparison of sprotte and quincke needle with respect to the PDPH and backache. Reg Anaesth 1992;17(5):283-7.

5. Shnider SM, Levenson G. Anaesthesia for caesarian section In: Shinder SM, Levinson G editors anaesthesia for obstetricies. Baltimore: williams \& wilkins: 1987;2nd edition:159-78.

6. Lambert DH, Hurley RJ, Hertwig L, et al. Role of needle gauge and tip configuration on the production of lumbar puncture headache. Reg anaesth 1997;22(1):61-72.

7. Seeberger MD, Honfmannon, Staender S, et al. Repeated dural punctures increase the incidance of the PDPH. Anaesth analg 1996;82(2):302-5.

8. Oconner G, Gingrich R, Moffat M. The effect of spinal needlecdesign, size and penetration angle on dural puncture cerebral spinal fluid loss. A Ana J 2007;75(2):111-6.

9. Vandam LD, Dripps RD. Long term follow up of patients who received 10098 spinal anaesthetics: syndrome of decreaed intracranial pressure. JAMA 1956;161(7):58691.

10. Janik R, Dick W. Post spinal headache; its incidence following the median and paramedian techniques. Anaesthetist 1992;41(3):137-41.

11. Corbey MP, Berg P, Quaynor H. Classification and severity of post dural puncture headache: comparison of $26 \mathrm{G}$ and $27 \mathrm{G}$ quincke's needle for spinal anaesthesia in day care surgery in patients under 45 years. Acta Anaesthesiol Scand 1997;41:779-84.

12. Santanen U, Aautoma P, Luurila H, et al. Comparision of 27 gauge whitacre and quincke's spinal needles with respect to postdural puncture headache and non dural puncture headache. Acta Anaesthesiol Scand 2004;48(4):474-9.

13. Flaatten H, Felthaus J, Wisborg T. Post dural puncture: a prospective randomized study and a meta analysis comparing two different $0.4 \mathrm{~mm}$ O.D (27G) spinal needles. Acta Anaesthesiol Scand 2000;44:643-7.

14. Kumar CM, Dennison B. Post spinal headache occurs much less with pencil point needles. Anaesthesia 1986.

15. Kaplan G. The psychogenic aetiology of postdural puncture headache. Psychomatic Medicine 1967;29(4):376-9. 